\title{
CHARACTERIZATION OF A LITHIUM FORMATE EPR-DOSIMETRY SYSTEM FOR PROTON RADIATION THERAPY
}

Tatiana Costa, Emelie Adolfsson, M. Fager and Eva Lund

The self-archived postprint version of this journal article is available at Linköping University Institutional Repository (DiVA):

http://urn.kb.se/resolve?urn=urn:nbn:se:liu:diva-164696

N.B.: When citing this work, cite the original publication.

Costa, T., Adolfsson, E., Fager, M., Lund, E., (2019), CHARACTERIZATION OF A LITHIUM FORMATE EPR-DOSIMETRY SYSTEM FOR PROTON RADIATION THERAPY, Radiation Protection Dosimetry, 186(1), 83-87. https://doi.org/10.1093/rpd/ncy293

Original publication available at:

https://doi.org/10.1093/rpd/ncy293

Copyright: Oxford University Press (OUP) (Policy B - Oxford Open Option A)

http://www.oxfordjournals.org/ 


\title{
CHARACTERIZATION OF A LITHIUM FORMATE EPR DOSIMETRY SYSTEM FOR PROTON RADIATION THERAPY.
}

\author{
T. Costa ${ }^{1}, \mathrm{E}$ Adolfsson ${ }^{2}$, M Fager ${ }^{3}$ and E Lund ${ }^{1}$ \\ ${ }^{1}$ Department of Medicine and Health Sciences, Linköping University, Linköping, Sweden \\ 2 Department of Medical Physics and Department of Medical and Health Sciences, Linköping University, \\ Linköping, Sweden \\ ${ }^{3}$ Department of Medical Radiation Physics and Nuclear Medicine, Karolinska University Hospital. Stockholm, \\ Sweden
}

\begin{abstract}
The specific aim for the characterization of the lithium formate dosimetry system is to determine response and stability in a proton beam. The long-term goal for this investigation is an audit system for proton therapy like the end-to-end dose determinations performed for radiotherapy with photons. For a $150 \mathrm{MeV}$ proton beam the dose response was found to be linear in the dose interval 0-8.8 Gy. The accuracy of dose reconstruction was controlled in a blind test, in which the dose of $6.63 \mathrm{~Gy}$ was measured in samples irradiated with a real dose of $6.70 \mathrm{~Gy}$ The stability was determined by irradiations of sets of 4 dosimeters every week during 1 month and analyzed at the same day thereafter. The fitting of the fading curve was done with a $2^{\text {nd }}$ order polynomial resulting in a $6.6 \%$ lower value compared to the reference after 31 days.
\end{abstract}

\section{INTRODUCTION}

Alanine has been the material of choice for EPR dosimetry for many years [1]. However, the relatively low sensitivity and a quite complex spectrum has introduced a search for materials with higher sensitivity. Among the other materials tested, lithium formate has shown to be a good candidate presenting a high yield and a simple EPR spectrum that results in a sensitivity up to 6 times that of alanine [2]. The lithium formate dosimetry system is well characterized in photon beams showing a linear dose response tested in the interval 0.2-30 Gy. The radicals are stable under normal laboratory conditions within at least 30 days and the dosimeters are robust against environmental influences if kept in constant humidity and in the dark [3].

Lithium formate EPR dosimeters have been used for accurate dose determinations in several clinical applications [4-7]. It is especially suitable for dose verifications when introducing new radiation therapy techniques and has showed great properties as a passive dosimeter at end-to-end dose determinations [8].

EPR dosimeter materials have been studied in different radiation qualities with different purposes. Alanine was studied in irradiations of protons from $1 \mathrm{MeV}$ to $16 \mathrm{MeV}$, in beams of ${ }^{40} \mathrm{Ca}$ and ${ }^{16} \mathrm{O}$ ions and the authors formulated a preliminary model for the decay in free radical concentrations at high LET, linear energy transfer, exposures [9]. Ammonium tartrate was characterized for clinical purposes and also in beams of light ions; $\mathrm{He}$ with LET $40 \mathrm{keV} / \mu \mathrm{m}, \mathrm{N}$ with
$125 \mathrm{keV} / \mu \mathrm{m}$ and $\mathrm{Ne}$ with $200 \mathrm{keV} / \mu \mathrm{m}[10]$. Lithium formate was earlier studied in proton beams with LET varying from $0.7-3.9 \mathrm{keV} / \mu \mathrm{m}$ and also in $\mathrm{N}$-ions with LET from $110-164 \mathrm{keV} / \mu \mathrm{m}$. [11]

The long term goal for this investigation is an audit system or end-to-end dose determinations for proton therapy. Even if the LET for $150 \mathrm{MeV}$ protons along the track well before the Bragg peak is between 0.5 and $1 \mathrm{keV} / \mu \mathrm{m}$ compared to $0.2 \mathrm{keV} / \mu \mathrm{m}$ for $4 \mathrm{MV}$ photons, the interactions between protons and matter are different from that of photons. Therefore, there is a need for careful characterization of the dosimeter material in the actual beam and our primary objectives are to investigate the dose response and radical stability in a clinical proton beam.

\section{MATERIAL AND METHODS}

\section{Dosimeters}

Polycrystalline lithium formate monohydrate is mixed with paraffin in proportions of $90 \%-10 \%$ and pressed to cylindrical tablets (diameter: $4.5 \mathrm{~mm}$; height: 4.9 $\mathrm{mm}$, weight $100.0 \pm 1.5 \mathrm{mg}$; maximum uncertainty). Details of the production procedure are given in [4]. Before use in any measurement in the proton beam the dosimeters are tested regarding the homogeneity of lithium formate in the tablets. The homogeneity tests are performed by pre-irradiation with 3 Gy photons and thereafter read-out. 
A batch of dosimeters is considered homogeneous if:

- $\quad$ No individual EPR signal deviates more than $2 \%$ from the average EPR signal of the batch.

- The relative standard deviation (RSD) of the signals of all dosimeters is lower than $1 \%$.

If any of these conditions is not verified the EPR signal values are corrected with a calculated individual calibration factor $\mathrm{C}_{\mathrm{i}}$.

$$
\mathrm{C}_{\mathrm{i}}=\mathrm{M}_{\mathrm{a}} / \mathrm{M}_{\mathrm{i}}
$$

where $\mathrm{C}_{\mathrm{i}}$ is the individual calibration factor of dosimeter $i, \mathrm{M}_{\mathrm{i}}$ is the measured EPR signal of dosimeter $i, \mathrm{M}_{\mathrm{a}}$ is the batch average EPR signal. The signal is not divided by the mass of the dosimeter since the individual calibration factor corrects for the amount of lithium formate in the dosimeter [12].

\section{Readout procedure}

The EPR signals are obtained using a BRUKER E500 EleXsys EPR spectrometer operating at X-Band and equipped with a standard ER4102ST resonator cavity. Each dosimeter is placed in the microwave cavity inside of a glass tube with flat bottom. The spectrometer settings were: microwave power $20 \mathrm{~mW}$, modulation frequency $100 \mathrm{kHz}$, modulation amplitude $1.2 \mathrm{mT}$, receiver gain $60 \mathrm{~dB}$, sweep width $3 \mathrm{mT}$ and sweep time $168 \mathrm{~s}$, resulting in a spectrum shape shown in Figure 1. No external reference was used in the resonator but to reduce possible instabilities of the spectrometer along the day, each dosimeter is read three to four times in a rotational schedule.

\section{Proton irradiations}

All proton irradiations were performed at the "Skandion clinic" (Uppsala) using a $150 \mathrm{MeV}$ scanned proton beam. In each irradiation, four dosimeters were positioned in a PMMA phantom with four holes drilled at the same distance to the center. The phantom is centered in a $10 \times 10 \mathrm{~cm}^{2}$ irradiation field, with $4 \mathrm{~mm}$ spot spacing. The phantom is placed above a slab of solid water for back-scatter and also slabs added on top to achieve an equivalent depth of $3 \mathrm{~cm}$ in water and placed so that an SSD of $200 \mathrm{~cm}$ is achieved. This setup is chosen since it resembles the reference dosimetry setup for $150 \mathrm{MeV}$ at this site, with the only change of solid water instead of water. At this depth the dose is stable and LET changes are smaller than 0.1 $\mathrm{keV} / \mu \mathrm{m}$ per $\mathrm{mm}$.

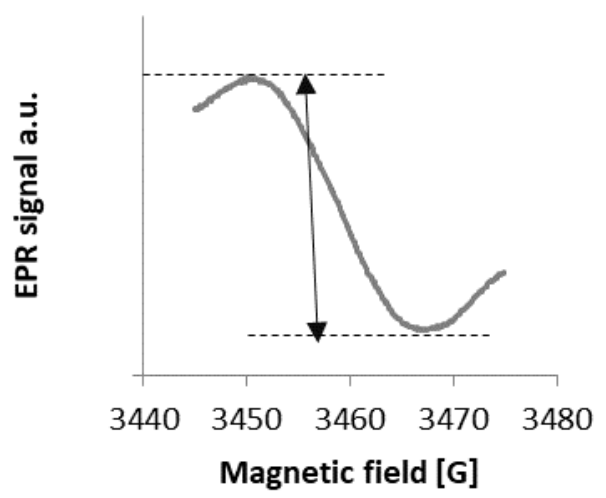

Figure 1. EPR spectrum of lithium formate where the arrow indicates the peak-to-peak amplitude, taken as the EPR signal.

\section{Response measurements}

A batch of 24 dosimeters tested for homogeneity was divided into six groups irradiated in the same day with: 0 Gy, 1.36 Gy, 2.72 Gy, 4.76 Gy, 6.80 Gy, and 8.84 Gy respectively to determine the linear dose response. In order to test the dosimeter response in a separate experiment three groups of four dosimeters were tested for homogeneity and irradiated in the proton beam with respectively $0 \mathrm{~Gy}, 7.90 \mathrm{~Gy}$ and one dose unknown for the experimentalist.

\section{Radical stability}

A batch of 24 dosimeters was tested for homogeneity and then divided in six groups of four dosimeters each and taken for storage to the Skandion clinic. Each seven days, one group was irradiated with the same dose 8.80 Gy. Additionally, one group was irradiated the last day, as the reference group (no signal fading considered). After all irradiations, the dosimeters EPR signals were read-out in the same day.

\section{RESULTS}

\section{Response measurements}

The relation between the absorbed dose and the EPR signal is shown in Figure 2 and Table 1 


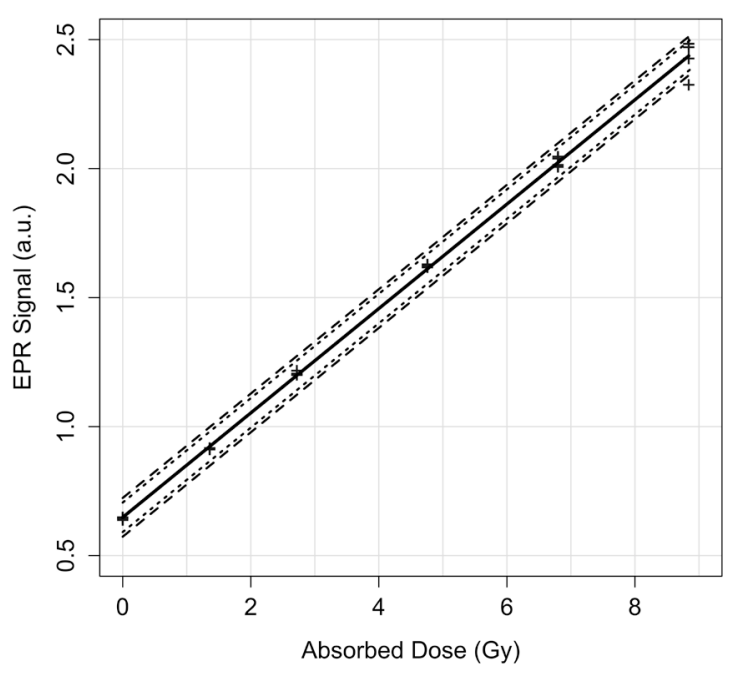

Figure 2. Relation between the EPR signal and the absorbed dose from the proton beam. . + measured values, - regression line. .... 95\% and ---- 95\% confidence interval.

Table 1. Summary of the EPR signal values with relative standard deviation and estimated values for absorbed dose together with the $95 \%$ confidence interval for the different groups of dosimeters corresponding to given radiation dose

\begin{tabular}{llll}
\hline $\begin{array}{l}\text { Given } \\
\text { dose } \\
\text { (Gy) }\end{array}$ & $\begin{array}{l}\text { EPR-signal } \\
\text { (a.u.) }\end{array}$ & $\begin{array}{l}\text { Estimated } \\
\text { dose } \\
\text { (Gy) }\end{array}$ & $\begin{array}{l}95 \% \text { confidence } \\
\text { interval } \\
(\mathrm{Gy})\end{array}$ \\
\hline 1.36 & $0.915 \pm 0.003$ & 1.32 & {$[1.04 ; 1.60]$} \\
2.72 & $1.206 \pm 0.007$ & 2.76 & {$[2.48 ; 3.04]$} \\
4.76 & $1.623 \pm 0.005$ & 4.83 & {$[4.46 ; 5.20]$} \\
6.80 & $2.027 \pm 0.019$ & 6.83 & {$[6.54 ; 7.11]$} \\
8.84 & $2.427 \pm 0.072$ & 8.81 & {$[8.52 ; 9.09]$}
\end{tabular}

The dose response is found to be linear,

$$
\mathrm{S}=((0.202 \pm 0.001) * \mathrm{D})+(0.648 \pm 0.003)
$$

where $\mathrm{S}$ is the EPR signal and $\mathrm{D}$ is the absorbed dose in water determined by the ionization chamber at the position of the dosimeters. The estimated doses from the different groups of dosimeters are derived from the regression line according to eq. 2 with the $95 \%$ confidence interval as shown in figure 2.

For the present investigation the critical dose is 0.28 Gy and the lowest detectable dose 0.56 Gy for the lithium formate dosimeter system, calculated according to L.A. Currie [13].

\section{The "blind" test}

Considering the dose response to be linear two calibration points are considered to be sufficient for determination of an unknown dose with the result given in table 2 .

Table 2. Summary of the measured EPR signal of each of the groups irradiated in the Blind Test.

\begin{tabular}{ccc}
\hline Dose & $\begin{array}{c}\text { Average EPR } \\
\text { Signal }\end{array}$ & $\begin{array}{c}\text { Signal Relative } \\
\text { Standard Deviation (\%) }\end{array}$ \\
\hline 0 & 0.478 & 1.3 \\
"blind" & 1.492 & 3.7 \\
7.90 & 1.688 & 3.8 \\
\hline
\end{tabular}

The absorbed dose for the "blind" detector was estimated to be $6.63 \pm 0.59 \mathrm{~Gy}$. The delivered unknown dose was $6.70 \pm 0.07 \mathrm{~Gy}$.

\section{Radical stability}

As shown In Table 3 the time between the irradiation and the readout is presented for each group, together with the average EPR-signal and the relative EPR Signal using group $f$ as the reference.

The best fitting to the experimental points was a polynomial regression given by Equation (2) and shown in Figure 3 The relative EPR signal: $\mathrm{S}_{\text {rel }}$ after the irradiation, in days: $\mathrm{d}$.

$$
\mathrm{S}_{\text {rel }}=\left((6.012 \mathrm{E}-5) * \mathrm{~d}^{2}\right)-(4.275 \mathrm{E}-3) * \mathrm{~d}+1.0
$$

The obtained results show a signal fading of $6.5 \%$ in a period of 31 days. 
Table3. Summary of the measured EPR signal of each of the groups irradiated over the weeks in the Fading Test.

\begin{tabular}{ccccc}
\hline Group & $\begin{array}{c}\text { Time between } \\
\text { irradiation and } \\
\text { readout (days) }\end{array}$ & $\begin{array}{c}\text { Average } \\
\text { EPR Signal }\end{array}$ & $\begin{array}{c}\text { Relative } \\
\text { EPR Signal }\end{array}$ & $\begin{array}{c}\text { Fading } \\
(\%)\end{array}$ \\
\hline$a$ & 31 & 1.944 & 0.936 & 6.4 \\
$b$ & 24 & 1.943 & 0.936 & 6.5 \\
$c$ & 17 & 1.996 & 0.961 & 3.9 \\
$d$ & 10 & 2.010 & 0.968 & 3.2 \\
$e$ & 3 & 2.075 & 0.999 & 0.1 \\
$f$ & 2 & 2.077 & 1.000 & 0.0 \\
\hline
\end{tabular}

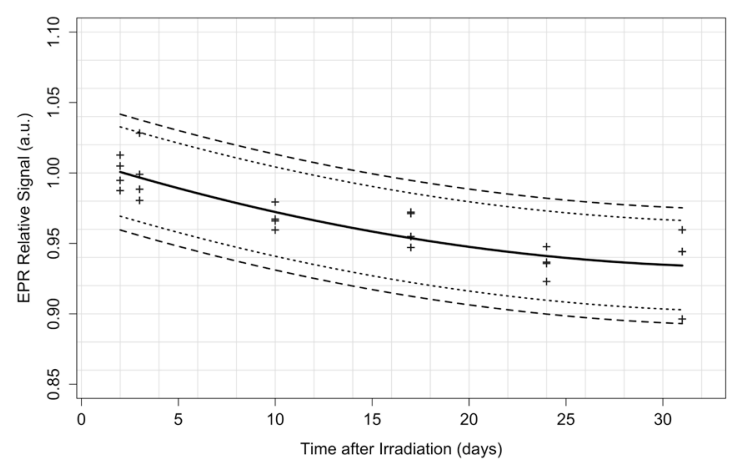

Fig 3. Relation between the relative EPR signal and the time between irradiation and signal read-out, in days. + measured values, - regression line. .... 95\% and ---- 95\% confidence interval.

\section{DISCUSSION}

The lithium formate dosimetry system is well characterized for photon irradiations but not for radiation qualities with particles. The most important properties when characterizing the dosimeters are the dose response and radical stability. Both are dependent on radical formation and recombination that might vary with the radiation quality.

The dose response was found to be linear as shown in Figure 2. The standard deviation of the signals from the 4 tablets for any of the 5 dose values above 0 is less than $1 \%$ except for 8.8 Gy $(<3 \%)$. This results in an uncertainty of the dose determinations about \pm 0.35 Gy with $95 \%$ confidence. However regarding the calibration curve obtained for the blind test the scatter is about $4 \%$ for the dose point 7.90 Gy resulting in the estimation of the blind dose to be $6.63 \pm 0.59 \mathrm{~Gy}$.

Regarding the higher uncertainty in the determination of an unknown dose we have noticed that the uncertainty increases with higher proton doses, see tables 1 and 2. The proton irradiation is given in 4 intervals to produce $7.90 \mathrm{~Gy}$ and an explanation for the increasing uncertainty with more dose fractions might be an angular dependence caused by differences in the scanning proton beam. Contrary to the proton irradiations the homogeneity tests are performed in the $\mathrm{X}$-ray beam from a linear accelerator which is usually completely flattened at the position were the irradiations are performed and the irradiations are given in one sequence. No angular difference has been found in the photon irradiations. In a future proton experiment the set of dosimeters should be rotated to compensate for angular variations during irradiations.

Already in the eighties it was found [9] that the radical stability was dependent on the LET and the particle mass. The fading in the present investigation was found to be $6.5 \%$ within one month contrary to photon irradiations performed in the same manner [3] where no fading was determined. This signal instability must be taken into account when lithium formate dosimeters will be used for dosimetry in a clinical proton beam. Correction factors for the stability of the dosimetric EPR signal must be established after repeated and prolonged investigations of the radical stability. Recently Carlino et al. in a thorough investigation reported that alanine pellets are suitable detectors for end-to-end tests in proton beam therapy [14]. With accurate corrections the lithium formate EPR dosimetry system can be used for dose verifications in a clinical proton beam and with a suitable choice of phantom material also for end-to-end tests in proton beams.

\section{CONCLUSION}

This work was the start to characterize lithium formate EPR dosimeters to be used for accurate dose determination in a clinical proton beam. It has been shown that the dose response is linear up to at least 9 Gy which is 4 times the standard dose fraction in proton therapy. The uncertainty in the dose estimations is less than $\pm 0.3 \mathrm{~Gy}(2 \mathrm{SD})$ and the lowest detectable proton dose was estimated to $0.56 \mathrm{~Gy}$. A test of the system showed that a "blind" dose could be determined to $6.63 \pm 0.59$ Gy for a delivered dose of $6.70 \pm 0.07 \mathrm{~Gy}$. However, the radical stability needs to be taken into 


\section{SHORT TITLE}

account if the time between irradiation and EPR signal readout is longer than three days. These results are promising for the use of a lithium formate dosimetry system for accurate dose determinations and verifications of proton irradiations.

\section{FUNDING}

This work was supported by the Swedish Cancer foundation (CF), contract number 110322 .

\section{REFERENCES}

1. Regulla D.F. and Deffner U., Dosimetry by ESR Spectroscopy of Alanine, J. Appl. Radiat. Isot. 33, 1101-1114, (1982).

2. Lund E., Gustafsson H, Danilczuk M., Sastry M.D., Lund A., Vestad T. A., Malinen E., Hole E.O. and Sagstuen E., Formates and dithionates: sensitive EPR-dosimeter materials for radiation therapy. Appl. Radiat. Isot. 62, 317-324 (2005).

3. Adolfsson E., Karlsson M., Alm Carlsson G., Carlsson Tedgren Å., Lund E., Olsson S. and Gustafsson H., Investigation of signal fading in lithium formate EPR dosimeters using a new sensitive method. Phys. Med. Biol. 57, 2209-2217 (2012).

4. Antonovic L., Gustafsson H., Alm Carlsson G. and Carlsson Tedgren Å., Evaluation of a lithium formate EPR dosimetry system for dose measurements around Ir-192 brachytherapy sources, Medical Physics, 36, (6), 2236-2247 (2009).

5. Gustafsson H., Lund E., Olsson S., Lithium formate EPR dosimetry for verifications of planned dose distributions prior to intensity-modulated radiation therapy. Physics in Medicine and Biology, 53, (17), 4667-4682 (2008),

6. Adolfsson E., Alm Carlsson G., Grindborg J.-E., Gustafsson H., Lund E. and Carlsson Tedgren Å., Response of lithium formate EPR dosimeters at photon energies relevant to the dosimetry of brachytherapy, Medical physics, 37(9), 49464959 (2010).

7. Vestad, T.A., Malinen, E., Olsen, D.R., Hole, E.O., Sagstuen, E.,. Electron paramagnetic resonance (EPR) dosimetry using lithium formate in radiotherapy: comparison with thermos-luminescence (TL) dosimetry using lithium fluoride rods. Physics in Medicine and Biology 49, 47014717, (2004).

8. Adolfsson E., Gustafsson H., Lund E., Alm Carlsson G., Olsson S. and Carlsson Tedgren Å., A system for remote dosimetry audit of 3D-CRT, IMRT and VMAT based on lithium formate dosimetry. Radiotherapy and Oncology, 113, (2), 279-282 (2014).

9. Hansen J.W. and Olsen K.J, Predicting Decay in Freeradical Concentrations in L- $\alpha$-Alanine Following High-LET Radiation Exposures, Appl. Radiat. Isot, 40, (10-12), 935-939 (1989).

10 Olsson S.K., Lund E. and Lund A., Development of ammonium tartrate as an ESR dosimeter material for clinical purposes, Appl. Radiat. Isot. 52, 1235-124 (2000).

11. Waldeland E., Hole E. O., Stenerlöw B., Grusell E., Sagstuen E. and Malinen E., Radical formation in Lithium formate EPR Dosimeters after irradiation with Protons and Nitrogen Ions. Radiation Research 174, 251-257 (2010).

12. Adolfsson E., Carlsson Tedgren Å., Alm Carlsson G., Gustafsson H. and Lund E., Optimization of an EPR dosimetry system for robust and high precision dosimetry, Radiation Measurements, 70, 21-28, (2014).

13. Currie L. A., Limits for qualitative detection and quantitative determination- application to radiochemistry, Anal. Chem. 40, 586-593 (1968)

14. Carlino A., Gouldstone C., Kragl G., Traneus E., Marrale M., Vatnitsky S., Stock M. and Palmans H, End to end tests using alanine dosimetry in scanned proton beams, Phys. Med. Biol. 63055001 (2018). 